\title{
A HOLISTIC APPROACH TO THE TREATMENT OF IRRITABLE BOWEL SYNDROME
}

\section{Prof. HG (Gertie) Pretorius}

D. Litt. et Phil.

Department of Psychology, Rand Afrikaans University

\section{Prof. AD (Anita) Stuart}

D. Litt. et Phil.

Department of Psychology, Rand Afrikaans University

\section{Ms LM (Lynda) Dolan}

MA (Counselling Psychology)

Department of Psychology, Rand Afrikaans University

\section{Ms K (Karina) de Bruin}

Department of Psychology, Rand Afrikaans University

\begin{abstract}
The purpose of this study is to investigate the effects of a holistic intervention approach to the management of Irritable Bowel Syndrome (IBS). The sample consisted of 70 South African women who were diagnosed with IBS. The sample was divided into four groups. Group $1(n=13)$ received IBS medication and holistic psychotherapy, Group $2(n=23)$ received IBS medication only, Group $3(n=13)$ received holistic psychotherapy only and Group $4(n=21)$ received no treatment until the study was completed. During the intervention phase the relevant participants received one-hour holistic psychotherapy per week for eight to twelve weeks. Medication as a treatment continued uninterrupted depending on each client's unique symptom patterns. The results of the study indicate that Group 1, who received IBS medication and holistic psychotherapy and Group 3 (holistic psychotherapy only) improved most in term of IBS symptom severity. Thus it is concluded that a holistic approach for the treatment of IBS is indicated, depending on the nature and severity of symptoms as well as each individual's contextual situation. This study facilitates a framework for psychologists who are working with clients with IBS or any other mind-body illness.
\end{abstract}

\section{OPSOMMING}

Die doelwit van die studie is om die effek van 'n holistiese benadering tot die bestuur van Prikkelbare Dermsindroom ("Irritable Bowel Syndrome") te ondersoek. Die steekproef het bestaan uit 70 Suid-Afrikaanse vroue wat gediagnoseer is met Prikkelbare Dermsindroom. Die steekproef is in vier groepe verdeel. Groep $1(n=13)$ het medikasie en holistiese psigoterapie ontvang, Groep $2(n=23)$ het slegs medikasie ontvang, Groep $3(n=13)$ het slegs holistiese psigoterapie ontvang en Groep $4(n=21)$ het geen behandeling ontvang totdat die studie afgehandel is nie. Gedurende die intervensiefase het die betrokke deelnemers holistiese psigoterapie ontvang vir een uur per week, vir agt tot twaalf weke. Medikasie as behandeling het deurentyd voortgegaan afhangende van elke kliënt se unieke patroon van simptome. Die resultate van die studie dui aan dat Groep 1, wat medikasie en holistiese psigoterapie ontvang het asook Groep 3 (slegs holistiese psigoterapie) die meeste verbetering ten opsigte van die ernstigheid van simptome getoon het. Die studie verskaf ' $n$ raamwerk vir sielkundiges wat met kliënte werk met Prikkelbare Dermsindroom of enige ander liggaam-gees siekte. 


\section{INTRODUCTION}

The past medical approach to Irritable Bowel Syndrome, which sought specific causes and diagnosis for the disorder, lacked a clear conceptual model of the nature of the syndrome. To date no recognisable characteristic physical abnormality has been identified to explain all the symptoms of the disorder (Drossman, 1998). Moving away from the traditional medical approach, current thinking points towards the role of both physiological and psychological factors in the development of symptoms in Irritable Bowel Syndrome patients, locating the disorder within the broader biopsychosocial context of which the individual is part (Stuart, Pretorius, Van der Merwe, 1999:45 46).

In the present study it is proposed that health care professionals, including psychologists, need to recognise the multi-dimensional nature of the syndrome and provide the patient with a deeper understanding of the functional and non-life threatening but chronic nature of his or her illness. The proposed intervention is an attempt to embrace individual functioning in interaction with wider contexts in a dynamic and holistic treatment of Irritable Bowel Syndrome. Such an approach includes not only pharmacological interventions, but also psychological treatments, which focus on each individual's subjective experience of the disorder, as well as their wider systems.

\section{DEFINITION}

Irritable Bowel Syndrome is a widespread functional disorder of the lower gastrointestinal tract, characterised by chronic or recurrent gastrointestinal symptoms without structural or biochemical abnormalities (Almounajed \& Drossman, 1996:477). Irritable Bowel Syndrome has been referred to as a psychosomatic syndrome (Keller, 1994:4), implying a complex set of symptoms that includes both subjective experiences and objective signs. Terms such as 'mucous colitis', 'spastic colon', 'irritable colon', and 'colonic neurosis' have previously been used to refer to the symptoms of Irritable Bowel Syndrome (Christensen, 1992:1444), but 'Irritable Bowel Syndrome' has gradually become the generally accepted term.

In order to receive a diagnosis of Irritable Bowel Syndrome, the patient must have continuous or recurrent abdominal pain or discomfort for three months that is associated with bowel dysfunction (Almounajed \& Drossman, 1996:477). In addition to identifying these symptoms, a medical history facilitates the identification of physical symptoms such as fever and bleeding, as well as factors that may mimic or exacerbate the disorder, for example lactose intolerance, inadvertent sorbitol ingestion and drug use.

\section{ETIOLOGY OF IRRITABLE BOWEL SYNDROME}

Various physiological and psychological factors are thought to contribute to the development of Irritable Bowel Syndrome in patients. Physiological factors include the role of disordered motility, referring to the movements of the gastrointestinal tract relating to the passage and processing of ingested food through the gastrointestinal lumen (Thompson, 1995:371). An understanding of the brain-gut interaction has also been used to provide insight into the development of Irritable Bowel Syndrome symptoms (Lydiard, 1997:52-53). Neural pathways between the brain and the gut interact in a coordinated way to exchange information. This helps to explain how patients with anxiety disorders could experience gastrointestinal distress during pathological arousal followed by afferent input from the gut back to important areas of the central nervous system.

Regarding psychological factors, the incidence of generalised anxiety disorder, somatisation disorder, panic disorder, and major depression (Walker, Roy- 
Byrne, Katon, Li, Amos \& Jiranek, 1990:1656), as well as interpersonal sensitivity, hypochondriasis and hostility (Whitehead, Engel \& Schuster, 1980:404) appear to be higher in patients with Irritable Bowel Syndrome than in control populations. Abnormal illness behaviour, referring to the different ways in which a person perceives, evaluates and acts upon a given illness, is also suggested by the high prevalence of psychiatric diagnosis, personality disturbance, depression and current life stress (Drossman, 1991:77-78). The literature further abounds with the large number of Irritable Bowel Syndrome patients who report endless life events such as career and family concerns (Enck \& Weinbeck, 1993:980), early childhood deprivation and a history of sexual or physical abuse among women as frequent stressors (Scarinci, McDonald-Haile, Bradley \& Richter, 1994:108). According to Drossman (1998:000) psychosocial trauma may lead to physiological and even anatomical alterations, which could explain symptoms, behaviour and the clinical outcome.

Although it is clear that various factors may contribute to the development of symptoms, the literature negates the uniformity of findings and it appears as if specialists are often polarised into those who believe that there is a definite underlying abnormality of gastrointestinal pathology and those who consider the condition to be purely psychological (Prior, 1994:328). It seems however that there is no specific or linear etiology for Irritable Bowel Syndrome, therefore current thinking focuses on an individualised approach to the understanding of the disorder. This approach points towards the complex and dynamic interaction between physiological and psychological factors to induce and modify pain and other symptoms in Irritable Bowel Syndrome patients (Almounajed \& Drossman, 1996:480).

\section{THERAPEUTIC INTERVENTIONS IN IRRITABLE BOWEL SYNDROME}

The available literature highlights the various treatment models for Irritable Bowel Syndrome.
These include physiological interventions such as pharmacology (Gorard, Libby \& Farthing, 1995:86) and psychopharmacology (Clouse, 1994:23522353). Although a universally effective drug for the treatment of the Irritable Bowel Syndrome symptom complex has not been found (Klein, 1988:233), medication may be helpful in the treatment of specific symptoms, such as to relieve constipation, diarrhoea or abdominal pain.

Dietary manipulation is also often used in an attempt to relieve Irritable Bowel Syndrome symptoms. Although many patients may attribute specific food substances to their symptoms, the type of food does not generally contribute to symptoms. Patients are more likely to experience a generalised effect of food ingestion on intestinal reactivity. However, certain substances, such as fatty foods, alcohol and caffeine, may aggravate symptoms in some individuals (Friedman, 1991:313). Contradictory results have been found regarding the effect of fibre supplementation on symptoms of Irritable Bowel Syndrome (Prior, 1994:330).

More recently, psychoneuroimmunology, which emphasises the impact of the central nervous system on the immune system, as well as kinesiology (the study of the effect of muscles on bodily and mind processes), have also been attempted as therapeutic interventions in the treatment of Irritable Bowel Syndrome (Levy \& Lehr, 1996:20). These are relatively new fields and controlled studies are necessary in order to facilitate scientific validation.

Due to the fact that psychosocial factors have been implicated in Irritable Bowel Syndrome, the importance of psychological interventions in the management of Irritable Bowel Syndrome cannot be ignored. These include behavioural interventions which focus on progressive relaxation (Blanchard, Greene, Scharff \& Schwarz-McMorris, 1993:125), transcendental meditation and yoga (Drossman, 1995:688), biofeedback (Denis, 1994:74) and stress management training (Whitehead, 1992:606). Cognitive therapy (Greene \& Blanchard, 
1994:576), cognitive-behavioural therapy (Neff \& Blanchard, 1987:70) and psychoanalytic therapy (McDougall, 1989:2) have also been successfully used in the treatment of Irritable Bowel Syndrome.

The purpose of this study is to investigate the effects of a holistic intervention approach to the management of Irritable Bowel Syndrome.

\section{PARTICIPANTS}

The sample consisted of 70 South African women (average age was 36 years) who were diagnosed with IBS by a medical doctor, and who presented with moderate to severe IBS symptoms. The participants were recruited from a number of sources. The IBS group were invited to participate in this study by means of articles that were published in various newspapers, magazines and a medical journal. These participants thus comprised individuals who had read these articles and volunteered themselves as research participants or had been referred by their medical doctor. This sample may not represent the general Irritable Bowel Syndrome population, but rather a selfselected group of the health care seeking population. Of the 70 participants, 11 had not attained matriculation level, whilst 38 had attained tertiary levels of education. The remaining all had attained matriculation level. Sixty-four participants were employed outside the home in various fields. In terms of symptoms, 8 participants presented with diarrhoea predominant symptoms, 36 with constipation predominant symptoms and the remaining 26 with a combination of diarrhoea and constipation. Forty-nine women reported a family history of emotional and psychological problems.

\section{INSTRUMENTS}

\section{Selection instruments}

The Irritable Bowel Syndrome patients were requested to complete a biographical questionnaire, the Functional Bowel Disorder Severity Index (FBDSI) and an IBS Client Questionnaire, on the basis of which the selection of subjects took place. The biographical questionnaire was used to obtain information pertaining to a number of variables, including the nature of symptom presentation, method of referral, age, education level, occupation, economic status, number of children, family history of psychological problems, participation in physical exercise and interest in religion.

The IBS Client Questionnaire (Drossman, Thompson, Talley, Whitehead, Richter and Corazziari, 1992, in Drossman, 1994:469) was used to screen for symptoms according to specific subjectively experienced criteria relating to consistency of stool, and to verify a diagnosis of Irritable Bowel Syndrome. The nature of the symptoms is determined by questions focusing on the number of symptoms reported per day, consistency of stool, straining, a sense of urgency, and the passing of mucus during a bowel movement, incomplete evacuation and the experience of abdominal fullness, bloating or swelling.

\section{Measuring instrument}

The Functional Bowel Disorder Severity Index (FBDSI) was completed in order to serve as a quantitative measure of pre-test and post-test Irritable Bowel Syndrome severity. Drossman, Zhiming, Toner, Diamant, Creed, Thompson, Read, Babbs, Barreiro, Bank, Whitehead, Schuster, and Guthrie (1995:995) developed this standardised scoring system to select patients for treatment trials and to quantify illness severity as an outcome measure in response to clinical interventions. The FBDSI as adapted from Drossman et al. (1995) is shown in Appendix A.

Drossman et al. (1995:986-995) provide evidence that attests to the reliability of the Functional Bowel Severity Index based on the following findings:

(i) Visual analogue scales have been 
shown to be reliable and responsive in assessing pain severity.

(ii)

A diagnosis of chronic functional abdominal pain, and the frequency of physician visits is not likely to change during the time frame $(<2$ weeks $)$ within which test-retest reliability is established.

(iii) Repeating the FBDSI as a measuring instrument in another sample of IBS clients assessed the replicability of the scale. The distribution of scores closely approximated those of the original study, suggesting that the FBDSI can reliably determine the range of illness in replicated studies (Drossman et al. 1995:987).

The validity of the FBDSI scale was determined both in terms of face and convergent validity by means of regression analysis (Drossman et al. 1995:987). In terms of face validity, clients with more severe pain that remains constant and who frequently consult doctors are likely to be judged as having more severe illness. Convergent validity was established since the same items repeatedly emerged from several different types of regression methods. The Kruskal-Wallis test was used to test construct validity by comparing the FBDSI scores to the degree to which symptoms interfered with daily activities. The researchers found a significant association in the predicted direction with a chisquare result of 43.64 with 4 degrees of freedom at the 0.0001 level of significance.

\section{RESEARCH PROCEDURE}

The participants were allocated to four different groups, namely three experimental groups and a control group. The groups who received psychotherapy (Groups 1 and 3) were limited to 13 participants per group because of time and capacity limitations. The participants in Group $1(\mathrm{~N}=13)$ received one hourly sessions of holistic psychotherapy, once per week, for a period of eight to twelve weeks, depending on the nature and severity of symptoms. They also received medication, which was prescribed by their referring doctor. The participants in Group $2(\mathrm{~N}=23)$ received medication, which was administered and monitored by the referring doctor. These clients received no psychotherapeutic intervention. The participants in Group $3(\mathrm{~N}=13)$ received holistic psychotherapy that was administered by one of the researchers. These clients received no medication for their symptoms. The participants in Group $4(\mathrm{~N}=21)$ received neither psychotherapy nor medication for their symptoms, but were placed on a waiting list for treatment.

It was found that certain clients who presented for treatment were already receiving certain types of medication and it was thus impossible to manipulate and randomly assign clients to the four groups. However, to increase internal validity clients who were receiving medication were randomly assigned to Group 1 and Group 2. Clients who did not receive medication were randomly assigned to Group 3 and Group 4.

The subjects were initially assessed and diagnosed with Irritable Bowel Syndrome by their referring doctor who completed a client referral form confirming the diagnosis. Each subject attended an initial interview at the consulting rooms of the Centre for Counselling and Research at the Rand Afrikaans University. During this interview patients were informed about the aims of the study, which were to facilitate an understanding of Irritable Bowel Syndrome and to help them cope better with their symptoms. They also completed the biographical questionnaire, the IBS Client Questionnaire and the Functional Bowel Disorder Severity Index (FBDSI) during this interview. The IBS Client Questionnaire and the Functional Bowel Disorder Severity Index were completed again three months after the treatment had been completed. The psychotherapeutic treatment continued for a period 
of eight to twelve weeks depending on the client's nature and severity of symptoms. Medication as a treatment continued uninterrupted depending on each client's unique pattern of symptoms.

\section{RESULTS AND DISCUSSION}

The mean pre-test and post-test scores, as well as the standard deviations of the four groups for the Functional Bowel Disorder Severity Index (FBDSI) are summarised in Table 1.

Table 1: Mean scores and standards deviations for the FBDSI

\begin{tabular}{|c|c|c|c|c|c|}
\hline \multirow[t]{2}{*}{ Group } & \multirow[t]{2}{*}{$n$} & \multicolumn{2}{|c|}{ Pre-test } & \multicolumn{2}{|c|}{ Post-test } \\
\hline & & Mean & SD & Mean & SD \\
\hline 1 (Medication and psychotherapy) & 13 & 175.15 & 65.80 & 76.46 & 77.73 \\
\hline 2 (Me dication) & 23 & 167.22 & 73.38 & 155.09 & 70.14 \\
\hline 3 (Psychotherapy) & 13 & 123.31 & 57.21 & 56.46 & 55.63 \\
\hline 4 (Control) & 21 & 186.33 & 58.12 & 159.14 & 75.13 \\
\hline
\end{tabular}

Inspection of the pre-test scores reveals an apparently meaningful difference between the mean FBDSI score of Group 3 and the remaining three groups. In terms of the post-test the mean scores of Group 1 and 3 appear to be similar and much lower than those of Groups 2 and 4.

Because comparison of post-test scores depend on the assumption that the pre-test scores are equal, an one-way ANOVA was performed on the pretest scores to test the null hypothesis that the four pre-treatment groups came from the same population. The critical region for rejection was set at $\mathrm{p}<0.05$. The results of the ANOVA are summarised in Table 2.

Table 2: One-way ANOVA results of the pretest scores for the FBDSI

\begin{tabular}{|l|l|l|l|l|l|}
\hline Source & Sum of squares & d.f. & Mean square & F value & Significance \\
\hline Between groups & 33494.800 & 3 & 11164.900 & 2.689 & 0.053 \\
Within groups & 27404.100 & 66 & 4152.137 & & \\
Total & 307536.000 & 69 & 73.380 & & \\
\hline
\end{tabular}

The results showed that the null hypothesis could not be rejected $(p=0.053)$. Computation of the omega square statistic (Howell, 1999:139) revealed that group membership accounted for approximately $7 \%$ of the variance in the pre-test FBDSI scores $\left(w^{2}=0.066\right)$. This finding suggests that although the differences between the mean scores of the four groups for the FBDI were not statistically significant, the groups were slightly different in a practical sense.

Because the differences between the mean pre-test FBDI scores were not statistically significant and group membership accounted for only a relative small amount of variance in the FBDSI scores, it was decided to assess the effects of the interventions through a simple one way ANOVA of the mean FBDSI post-test scores.

The results of the one-way ANOVA of the posttest scores are summarised in Table 3.

Table 3: One-way ANOVA results of the posttest scores for the FBDSI

\begin{tabular}{|l|l|l|l|l|l|}
\hline Source & Sum of squares & d.f. & Mean square & F value & Significance \\
\hline Between groups & 136814.000 & 3 & 45604.600 & 9.100 & 0.000 \\
Within groups & 330765.000 & 66 & 5011.589 & & \\
Total & 467579.000 & 69 & 73.380 & & \\
\hline
\end{tabular}

These results revealed a significant difference between one or more of the mean post-test FBDSI scores $(p=0.000)$. The omega squared statistic suggested that group membership accounted for approximately $7 \%$ in the pre-test scores. It thus appears that the interventions resulted in statistically and practically significant differences in the post-test FBDSI scores.

In order to locate the specific differences between the four groups, a post-hoc Scheffe test was conducted. These results are summarised in Table 4.

\section{Table 4: Results of the post-hoc Scheffe test}

\begin{tabular}{|l|l|l|}
\hline Groups & Mean difference & Significance \\
\hline Group 1 versus Group 2 & -78.630 & $0.022^{*}$ \\
Group 1 versus Group 3 & 20.000 & 0.914 \\
Group 1 versus Group 4 & -82.680 & $0.017^{*}$ \\
Group 2 versus Group 3 & 98.630 & $0.002^{* *}$ \\
Group 2 versus Group 4 & -4.060 & 0.998 \\
Group 3 versus Group 4 & -102.680 & $0.02^{*}$ \\
\hline *The mean difference is significant at the 0.05 level \\
*- The mean difference is significant at 0.01 level
\end{tabular}


Inspection of this table reveals statistically significant differences between the means of:

(a) Group 1 (Medication and psychotherapy) and Group 2 (Medication only),

(b) Group 1 (medication and psychotherapy) and Group 4 (Control),

(c) Group 2 (Medication only) and Group 3

(Psychotherapy only), and

(d) Group 3 (Psychotherapy) and Group 4 (Control).

Inspection of the mean scores in Table 1 shows that Group 1 (Medication and psychotherapy) and Group 3 (Psychotherapy) obtained lower FBDSI post-test scores than the remaining two groups.

The above findings suggest that holistic psychotherapy was the most effective form of treatment for IBS. It is concluded that holistic psychotherapy resulted in the most favourable outcome due to the individualised nature of the therapy and the fact that there was no specific emphasis on one particular subsystem, such as the biological subsystem where medication would suffice. Furthermore, a broader focus on the person's physiological subsystem includes addressing all physical aspects such as diet, homeopathy and physical fitness. The emphasis in holistic psychotherapy is placed on each client's subjective experience of IBS as well as their unique situation.

It is important however, to note some of the limitations of the study. Firstly, statistical analysis such as was performed in this study, reduces a complex and subjective syndrome such as IBS to generalised results which leads to objective interpretations and lack of understanding of each individual's subjective expression of the symptoms in their lives. Individual differences that may provide significant information are thus ignored.

Secondly, the sample selection process was quite diverse and may have provided a self-selected sample of health care seekers. Thus the ability to generalise findings beyond the scope of the study sample is limited.

In the present study participants were randomly assigned to the psychotherapeutic treatment groups, however, medication was not randomly assigned to all four groups due to the ethical problems associated with drug administration as well as the effects of client choice of treatment on expected outcome. Some clients were already receiving medication, which had been prescribed by their doctor. This poses a limitation on the study due to the lack of randomisation on the medication variable. Furthermore, limitations were found with regards to monitoring concurrent drug use in the group who received medication only as well as the control group.

The participants who were assigned to the control group, as well as clients who received medication only, were placed on a waiting list for treatment. It can be argued that these subjects may have developed expectations as a result of being placed on the waiting list, which may have had an effect on the outcome of the study.

Lastly, blindedness was limited as the outcome assessor was known to the subjects who received the treatments. The validity of the results is therefore limited.

Strengths of the study include the use of a standardised IBS definition, an adequate sample size that was found to be an improvement on most previous studies. The trial length of 8 to 12 weeks allowed for the placebo response to settle and to control for the fluctuating nature of IBS.

\section{RECOMMENDATIONS}

In view of the above findings and an examination of the statistical findings it is recommended that future research in this area should combine quantitative and qualitative research. Such a holistic 
interpretation would include some of the more salient findings, which incorporate a discussion on the magnitude of therapeutic change.

Future trials should also compare holistic psychotherapy with various other forms of psychotherapy in order to determine whether there are any improved effects in outcome between a single therapeutic approach versus a holistic therapeutic approach.

Lastly, future South African studies should include a more diverse sample to assist all members of the South African population in the management of their IBS symptoms.

\section{CONCLUSION}

From the results of the study it is clear that the patients who received medication and psychotherapy, as well as the ones receiving psychotherapy alone, showed the most improvement. Seeing that holistic psychotherapy was utilised in both instances, it can be concluded that this intervention resulted in the most favourable outcome. It is the thesis of the present study that all factors affecting intervention designs, including both specific and non-specific factors, form part of the individual's experience and thus become part of the process of change. The individual's IBS symptoms become merely one expression of the more complex and dynamic nature of his/her life.

As you ought not to attempt to cure the eyes without the head, or the head without the body, then neither ought you attempt to cure the body without the soul...for the part will never be well unless the whole is well (Plato in Gatchel, 1993:1).

\section{APPENDIX A}

\section{Questionnaire to determine the severity of IBS symptoms}

\section{Question 1}

Please indicate the amount of abdominal pain you feel:

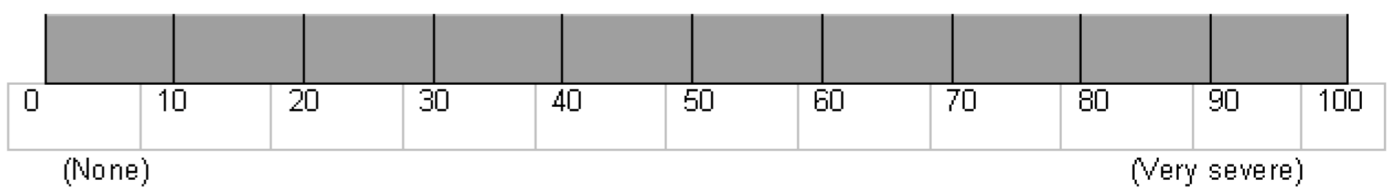

Question 2

How many visits have you made to your doctor for your bowel symptoms in the past three months? visits

\section{Question 3a}

For at least 3 months, have you had continuous or frequently occurring pain in your lower abdomen? (This should not be related to your menstrual cycle)

\begin{tabular}{|l|l|}
\hline 1. Yes & 2. No \\
\hline
\end{tabular}

\section{Question 3b}

Has this pain interfered with your daily activities from time to time? (e.g. inability to work or decrease in social events?)

\begin{tabular}{|l|l|}
\hline 1. Yes & 2. No \\
\hline
\end{tabular}


Scoring sheet for the use of the Functional Bowel Disorder Severity Index (FBDSI)

\begin{tabular}{|c|c|c|c|c|c|}
\hline Item & Score & $x$ & Factor & $=$ & Subtotal \\
\hline $\begin{array}{l}\text { 1. On a scale of } 0 \text { to } 100 \text {, indicate the amount of } \\
\text { abdominal pain you feel today: } \\
\text { None (0) } \\
\text { severe }\end{array}$ & 80 & $X$ & 1 & $=$ & 80 \\
\hline $\begin{array}{l}\text { 2. How many visits have you made to your doctor } \\
\text { for your bowel symptoms in the past three } \\
\text { months? }\end{array}$ & 7 & $X$ & 11 & $=$ & 77 \\
\hline $\begin{array}{l}\text { 3. Diagnosis of chronic functional abdominal } \\
\text { pain (to obtain a score of } 1 \text {, question } 3 a \text { and } \\
\text { 3b must be "Yes": } \\
1 \text { _ X__es) }\end{array}$ & 1 & $X$ & 106 & $=$ & 106 \\
\hline Add totals to give functional b & $10 x$. & & & tal & $=263$ \\
\hline
\end{tabular}

Cut-off scores:

$\begin{array}{lll}\text { Mild illness } & = & <36 \\ \text { Moderate illness } & = & 37-110 \\ \text { Severe illness } & = & >111\end{array}$

\section{REFERENCES}

ALMOUNAJED, G \& DROSSMAN, DA 1996: Newer aspects of Irritable Bowel Syndrome. Primary Care, 23(3):477-495.

BLANCHARD, EB; GREENE, B; SCHARFF, L \& SCHWARZ-MCMORRIS, SP 1993: Relaxation training as a treatment of Irritable Bowel Syndrome. Biofeedback and Self-Regulation, 18(3):125-132.

CHRISTENSEN, J 1992: Pathophysiology of the Irritable Bowel Syndrome. The Lancet, 340:1444-1452. CLOUSE, RE 1994: Antidepressants for functional gastrointestinal syndromes. Digestive Disease and Sciences, 39:2352-2363.

DENIS, P 1994: Biofeedback for constipation. (In: Kamm, MA \& Lennard-Jones, JE eds. 1994: Constipation. Petersfield, UK: Wrightson Biomedical.) DROSSMAN, DA \& THOMPSON, GT 1992: The Irritable Bowel Syndrome: review and a graduated multicomponent treatment approach. Annals of Internal Medicine, 116(12), (Part 1):1009-1016.

DROSSMAN, DA 1991: Illness behaviour in the Irritable Bowel Syndrome. Gastroenterology International, 4(2):77-81.

DROSSMAN, DA 1994: The functional gastrointestinal disorders: Diagnosis, Pathophysiology, and treatment A multinational consensus; first edition. Boston: Little Brown.
DROSSMAN, DA 1995: Diagnostic and treating patients with refractory functional gastrointestinal disorders. Annals of Internal Medicine, 123(9):688-697. DROSSMAN, DA 1998: Presidential address: Gastrointestinal illness and the biopsychosocial model. Psychosomatic Medicine, 60:000-000.

DROSSMAN, DA; ZHIMING, LI; TONER, BB; DIAMANT, NE; CREED, FH; THOMPSON, D; READ, $\mathrm{N}$; BABBS, C; BARREIRO, M; BANK, L; WHITEHEAD, WE; SCHUSTER, MM \& GUTHRIE, EA 1995: Functional bowel disorders: A multicenter comparison of health status and development of illness severity index. Digestive Diseases and Sciences, 40(5):986-995.

ENCK, P \& WEINBECK, M 1993: Epidemiology and psychological factors of the Irritable Bowel Syndrome.

European Journal of Gastroenterology and Hepatology, 5(12):979-989.

FRIEDMAN, G 1991: Diet and the Irritable Bowel Syndrome. Gastroenterology Clinics of North America, 20(2):313-324.

GATCHEL, RJ 1993: Psychophysiological disorders: Past and present perspectives. (In: Gatchel, RJ \& Blanchard, EB eds. 1993: Psychophysiological disorders: Research and clinical applications. Washington DC: American Psychological Association.) 
GORARD, DA; LIBBY, GW \& FARTHING, MJ 1995:

Effect of a tricyclic antidepressant on small intestinal motility in health and diarrhea predominant Irritable Bowel Syndrome. Digestive Diseases and Sciences, 40(1):86-95.

GREENE, B \& BLANCHARD, EB 1994: Cognitive therapy for Irritable Bowel Syndrome. Journal of Consulting and Clinical Psychology, 62(3):576-582. HOWELL, DC 1999: Fundamental statistics for the behavioral sciences. Pacific Grove: Duxbury.

KELLER, R 1994: Psychosomatic syndromes, somatization and somatoform disorders. Psychotherapy and Psychosomatics, 61:4-24.

KLEIN, KB 1988: Controlled treatment trials in the Irritable Bowel Syndrome: A critique. Gastroenterology, 95:232-241.

LEVY, SL \& LEHR, C 1996: Your body can talk: The art and application of clinical kinesiology. Prescott: Home Press.

LYDIARD, RB 1997: Anxiety and the Irritable Bowel Syndrome: Psychiatric, medical, or both? Journal of Clinical Psychiatry, 58(suppl. 3):51-58.

MCDOUGAL, J 1989: Theaters of the body: A psychoanalytic approach to psychosomatic illness. New York: Norton.

NEFF, DF \& BLANCHARD, EB 1987: A multicomponent treatment for Irritable Bowel Syndrome. Behavior Therapy, 18:70-83.

PRIOR, A 1994: Irritable Bowel Syndrome. Medicine International, 22(8):327-332.

SCARINCI, IC; MCDONALD-HAILE, JM; BRADLEY, LA \& RICHTER, JE 1994: Altered pain perception and psychosocial features among women with gastrointestinal disorders and history of abuse: A preliminary model. American Journal of Medicine, 9:108-118.

STUART, AD, PRETORIUS, HG \& VAN DER MERWE, L 1999: Irritable Bowel Syndrome: Towards an integrated approach. Health SA Gesondheid, 4(1):45 $-46$.

THOMPSON, DG 1995: Gastrointestinal motility. Medicine International, 22(9):370-374.

WALKER, EA; ROY-BYRNE, PP; KATON, WJ; LI, L; AMOS, D \& JIRANEK, G 1990: Psychiatric illness and Irritable Bowel Syndrome: A comparison with inflammatory bowel disease. American Journal of Psychiatry, 147(12):1656-1661.

WHITEHEAD, WE 1992: Behavioral medicine approaches to gastrointestinal disorders. Journal of Consulting and Clinical Psychology, 60(4):605-612. WHITEHEAD, WE; ENGEL, BT \& SCHUSTER, MM 1980: Irritable Bowel Syndrome: physiological and psychological differences between diarrhea-predominant and constipation-predominant patients. Digestive Diseases and Sciences, 25:404. 